\title{
Interplay between cardiac transcription factors and non- coding RNAs in predisposing to atrial fibrillation
}

\author{
Alexander T. Mikhailov ${ }^{1}$, Mario Torrado ${ }^{1}$ \\ ${ }^{1}$ Institute of Health Sciences University of A Coruña, A Coruña, Spain
}

\begin{abstract}
There is growing evidence that putative gene regulatory networks including cardio-enriched transcription factors, such as PITX2, TBX5, ZFHX3, and SHOX2, and their effector/target genes along with downstream non-coding RNAs can play a potentially important role in the process of adaptive and maladaptive atrial rhythm remodeling. In turn, expression of atrial fibrillation-associated transcription factors is under the control of upstream regulatory non-coding RNAs. This review broadly explores gene regulatory mechanisms associated with susceptibility to atrial fibrillationwith key examples from both animal models and patients-within the context of both cardiac transcription factors and non-coding RNAs. These two systems appear to have multiple levels of cross-regulation and act coordinately to achieve effective control of atrial rhythm effector gene expression. Perturbations of a dynamic expression balance between transcription factors and corresponding non-coding RNAs can provoke the development or promote the progression of atrial fibrillation. We also outline deficiencies in current models and discuss ongoing studies to clarify remaining mechanistic questions. An understanding of the function of transcription factors and noncoding RNAs in gene regulatory networks associated with atrial fibrillation risk will enable the development of innovative therapeutic strategies.
\end{abstract}

\section{Keywords}

Atrial fibrillation; Gene regulatory networks; Transcription factors; Non-coding RNAs; Atrial myocardium 


\section{Introduction}

Atrial fibrillation (AF) is the most common sustained arrhythmia in current clinical practice. There are different predisposing risk factors and conditions for the development of $\mathrm{AF}$, but patients diagnosed with asymptomatic non-familiar AF do not have any traditional risk factors. Proarrhythmogenic molecular remodeling, broadly defined as any change in atrial gene regulation that promotes atrial conduction disturbances, is potentially crucial for unraveling a sudden-onset of AF [1].

There is growing evidence that putative gene regulatory networks (GRNs) including cardio-enriched transcription factors (TFs) and their target genes can play a potentially important role in the process of adaptive and maladaptive atrial rhythm remodeling [2]. In addition, human genome-wide association studies (GWAS) have successfully identified chromosome loci of DNA variants associated with increasing risk for AF and their closest genes including those coding for cardio-enriched TFs (reviewed in $[3,4,5,6]$ ). Recently, a number of studies have demonstrated that cardiac GRNs are under the control of interleaved networks of regulatory non-coding RNAs (ncRNAs), which include microRNAs (miRNAs) and long noncoding RNAs (lncRNAs). Mature miR transcripts (approximately 22-nucleotide long) act as inhibitors of target gene expression by either promoting mRNA degradation or suppressing translation. In this context, lncRNAs (more than 200 nucleotides long) can either activate or suppress gene expression by regulating chromatin conformation and TF binding or through sequestering miRNAs from their target mRNAs. Contemporary research has revealed that ncRNAs are dysregulated in many forms of adult heart disease in both patients and animal models [7, 8]. In particular, it was evidenced that ncRNAs may form additional critical layers of the intricate modulator architecture for the control of atrial gene expression $[9,10,11,12,13,14,15]$.

This review broadly explores the gene regulatory mechanisms associated with susceptibility to AF providing key examples within the context of both cardiac TFs and ncRNAs. These two systems appear to have multiple levels of cross-regulation and act coordinately to achieve effective control of atrial rhythm effector gene expression. Perturbations of expression balance between TFs and ncRNA networks can promote AF development. In this context, several lines of evidence indicate that the TF-miRNA blueprint for AF susceptibility is distinct from that associated with chronic AF [16, 17]. Accordingly, the aim of the present review is to summarize the current evidence on the role of the cardiac TF-ncRNA co-regulatory networks in predisposition to AF. Deciphering the interplay between cardiac TFs and ncRNAs will likely lead to a more translational approach for preventing and treating AF.

\section{Sources of atrial ectopic beats triggering fibrillation}

Spontaneous self-terminating episodes of AF are one of the most common heart rhythm disorders. Ectopic pacemaking activity (i.e., electrical impulse generation outside the sinoatrial node (SAN)) and re-entry of excitation wavefronts are considered the most probable mechanisms involved in AF development. There is a substantial body of research demonstrating that erratic atrial premature beats can trigger AF in the presence of a vulnerable substrate. Once initiated, AF itself can lead to the so-called electric remodeling of atrial myocardium, which promotes fibrillation maintenance [1].

Focal triggering sites of spontaneous $\mathrm{AF}$ can reside in various anatomical structures such as the left atrial (LA) appendage as well as LA myocardial muscle extensions ("sleeves") located in the pulmonary veins (PVs) (Fig. 1). The PVs are characterized by a unique myofiber architecture and electric properties that can lead to the ectopic activity that triggers AF, and PV ablation is widely used to terminate AF [18]. 


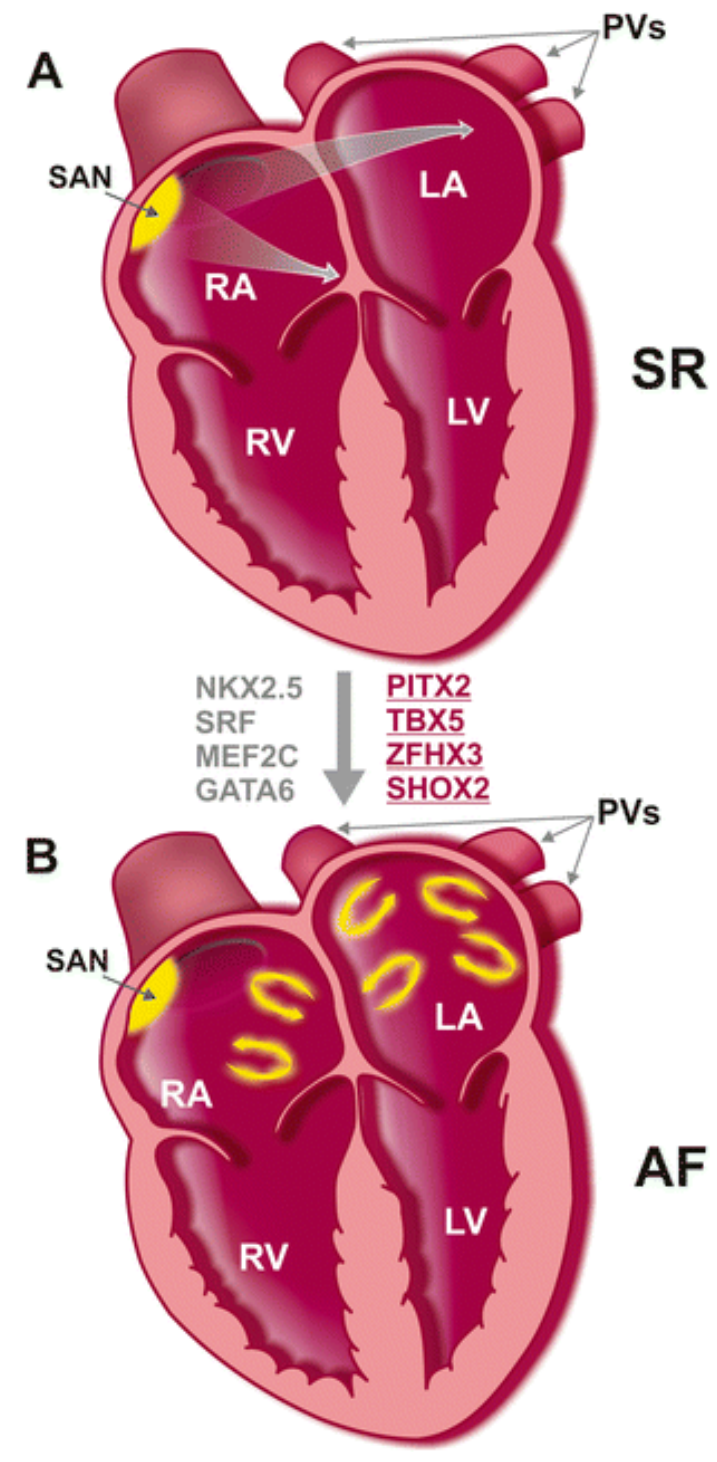

Fig. 1. Atrial activation patterns and transcription factors involved in the development of atrial fibrillation. a Normal atrial activation during sinus rhythm (SR). The sinus node (SAN) located at the entrance of the right superior cava vein in the right atrium (RA) generates electrical impulses which are distributed within large areas (big wide arrows) of the RA and left atrium (LA) to create normal rhythm. RV and LV right and left ventricles. b Atrial ectopic (non-SAN) rhythm activation. Ectopic pacemaking activity (semi-circular arrows) in the LA, pulmonary veins (PVs), or RA can trigger the development of atrial fibrillation (AF). Clinical studies have evidenced that more than $80 \%$ of the $\mathrm{AF}$ trigger impulses originate within $\mathrm{PV}$ muscular sleeves and LA muscles. NKX2.5, SRF, MEF2C, GATA-6, PITX2, TBX5, ZFHX3, and SHOX2 are the core cardiac TFs, which are thought to be responsible for initiation of AF. TFs implicated in susceptibility to AF by genetic and functional assays in animal models coupled with studies of samples from $\mathrm{AF}$ patients are marked in red, while those marked in gray have only sporadically been associated with an increased risk of AF. (Heart images taken from http://www.michiganmedicalreport.com/michigan_cardiology/details/241 /podcast.aspx, modified) 
Some clinical data suggest that the right atrium (RA) could also play a role in AF triggering [19]. However, the LA and RA have different susceptibilities toward developing arrhythmias: LA arrhythmias are more frequently observed [20]. Atrial mapping in patients shows that paroxysmal AF may originate in the RA in no more than $20-25 \%$ of cases [21, 22].

In adult mice as well as in humans, the LA and RA differ in their gene expression patterns $[23,24,25]$. In this sense, some cardio-enriched TFs and miRNAs [26, 27] involved in the development and progression of $\mathrm{AF}$ demonstrating left-right asymmetry in their expression in atrial myocardium. Within the scope of this review, the expression patterns of several of such TFs and miRNAs in the human left and right atria are schematically outlined in Fig. 2.
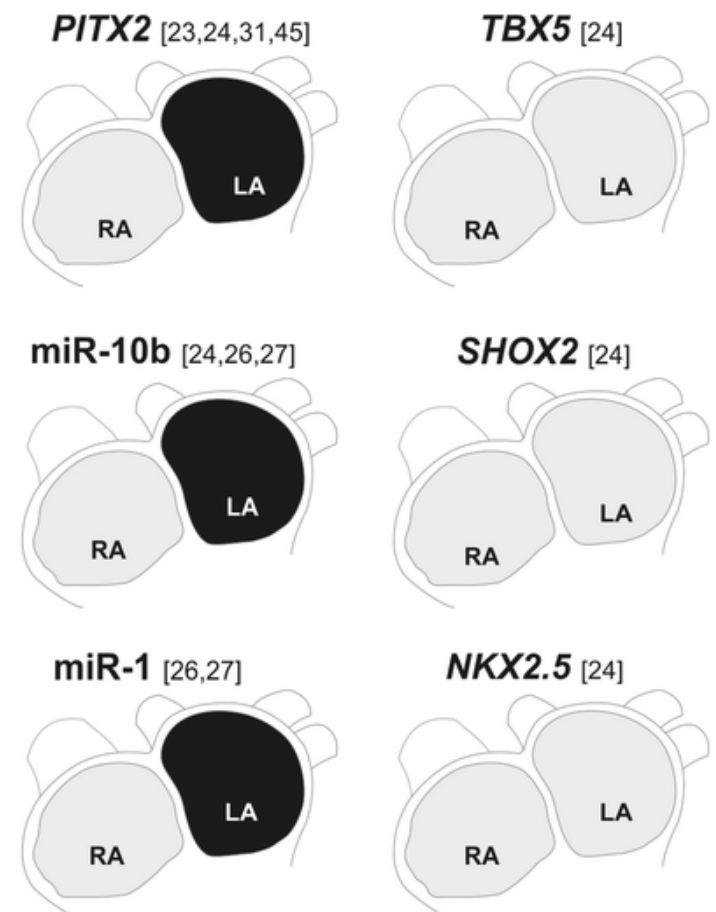

LA predominant

No differences

Fig. 2. Schematic representation of transcription factors and microRNAs expression signatures in human left and right atria. The color intensity is proportional to relative differences in expression levels of the gene in the RA vs LA; lightly gray denotes a relatively low while black denotes a relatively high expression. RA right atrium, LA left atrium. Respective references are shown in brackets

In addition to interatrial ectopic pacemaking activities, pathophysiological cardiac conditions, such as heart failure, valvular heart disease, hypertrophic cardiomyopathy, acute myocardial infarction, and congenital heart disease, can lead to AF development. Intriguingly, it was recently found that accumulation of atrial adipose tissue is associated with AF [28]. Moreover, it was evidenced that human adult atrial epicardial cells differentiate into adipocytes [29] that, in turn, can contribute, under certain conditions [30], to the formation of AF substrate. 


\section{Transcription factors-microRNA co-regulation in atrial fibrillation}

AF susceptibility is associated with rapid transcriptional remodeling of atrial myocardium. It is generally accepted that TFs and miRNAs jointly regulate target gene expression by either feed-forward or feedback mechanisms. However, the different roles of many TFs and miRNAs in the development of AF have been separately studied. In spite of such a mechanistic dissociation in the field of basic AF research, we will try to bring together the scattered findings on the atrial TF-miRNA circuits underlining $\mathrm{AF}$ susceptibility. The analysis of opposite correlations between TF and miRNA expression levels have allowed the identification of $\mathrm{TF}$-miRNA regulatory circuits which are of particular interest in the context of atrial predisposition to AF development.

\section{PITX2/miRNA circuits}

PITX2 (pituitary homeobox 2 or paired-like homeodomain transcription factor 2), a member of the bicoid class of homeobox genes, is located within the human 4q25 AFassociated locus. In humans, the gene is transcribed into four distinct variants: PITX2A, PITX2B, PITX2C, and PITX2D. PITX2C, the predominant cardiac variant of the gene, is more highly expressed in the adult LA compared to RA [31, 32, 33]. PITX2 has been extensively studied, particularly its functions in heart development. It is widely recognized that PITX2C implicated in multiple pathways of cardiac left-right $(\mathrm{L}-\mathrm{R})$ asymmetry [34, 35] also regulates $\mathrm{L}-\mathrm{R}$ atrial identity. The phenotype of PITX2C-deficient mice is characterized by RA isomerism with two SANs at both right and left regions of sinoatrial junction, each expressing the same panel of SAN-specific molecular markers [36]. Of note, pediatric patients with RA isomerism, usually with two SANs, are characterized by a high incidence of AF [37]. There is growing evidence suggesting that PITX2 plays a role in regulating gene expression as well as electrical, functional, and structural integrity in adult LA [38]. Of note, PITX2 and NKX2-5 control the development of LA myocardial "sleeves" in the PVs (see Fig. 1), the most frequent arrhythmogenic focus in patients with AF [39].

GWAS in humans revealed that genetic variants at chromosome $4 \mathrm{q} 25$ constitute the strongest locus associated with AF. Some of these $4 \mathrm{q} 25$ variants are located in the proximity of the PITX2 gene suggesting that modulations of PITX2 expression in atria are associated with susceptibility to AF development [40]. In this sense, CRISPR-Cas9mediated editing of one of the AF-associated $4 \mathrm{q} 25$ variants proximal to PITX2 in human stem cell-derived cardiomyocytes significantly downregulates PITX2C expression. This downregulation is most likely due to alteration of the TFAP2a (transcription factor AP-2 alpha) binding site(s) at the risk variant region that leads to inactivation of a putative PITX2 enhancer [41].

Loss-of-function mutations in PITX2 have been shown to be associated with familiar $\mathrm{AF}$ [42]. In addition, functional studies show that the mutation in the $5^{\prime}$ untranslated region of the PITX2 gene, identified in probands with severe AF, leads to downregulation of this gene expression in atrial myocytes at both basal conditions and rapid pacing [43]. Data from animal models are well in line with these findings. In mice, PITX2 haploinsufficiency predisposes to pacing-induced AF indicating that reduced PITX2 levels promote an arrhythmogenic substrate as observed in different mouse models [31, 44, 45, 46]. In addition, unstressed adult PITX2 mutant mice manifest electrocardiographic signs of sinus node dysfunction (SND) which is frequently associated with AF development in humans [47]. In this regard, it should be noted that the abnormal electrophysiological substrate for SND is localized in the RA while the majority of triggers and substrates for AF originate in the LA (see Fig. 1). Similarly to what has been observed in mice, there is an association between LA PITX2 downregulation and increased atrial arrhythmogenicity in a rat experimental model of hypertension with spontaneous atrial arrhythmias [48]. In model 
cell-based assays, PITX2 knockdown significantly decreases the expression level of the ZFHX3 TF which, in turn, may contribute to the occurrence of AF [49]. While experimental data from animal models of PITX2 knockdown do provide evidence that PITX2 deficiency can play a role in susceptibility to $\mathrm{AF}$, the results of transcriptomic profiling of atrial myocardium from patients with AF are not yet conclusive. Particularly, increased [50], decreased [45, 51], or unaltered [33] PITX2C levels were detected in atrial biopsy specimens from AF patients. PITX2 modulates atrial resting membrane potential and alters the effectiveness of $\mathrm{Na}$ channel blockers; antiarrhythmic agents were found to be more effective in suppressing arrhythmias in atria with reduced PITX2C mRNA levels [52]. In humans, AF risk single-nucleotide polymorphisms (SNPs) are associated with increased PITX2 expression [53]. These findings, taken together with the above data, indicate that the direct correlation between PITX2 expression levels in the atrial myocardium and a multifactorial disorder like human AF remains elusive. (For more details, see the comment [54].)

PITX2 can contribute to regulation of atrial contractility and arrhythmogenesis through multiple pathways including a variety of ion channel, calcium handling, and gap junction proteins that are crucial for atrial pacemaker activity [38]. In addition, the analysis of cardiac expression of multiple miRNAs regulated by PITX2 in the heart has yielded some interesting results in relation to the mechanisms by which PITX2 may modulate several pathways leading to AF $[2,38]$. PITX2 expression is co-localized with the expression of miR-17-92 and miR-106b-25 clusters and loss of PITX2 causes decreased expression of the corresponding miRNAs. Mice deficient in these miRNA clusters reveal characteristics similar to those of PITX2 mutant mice, including a high predisposition to induced AF and dysregulation of $S H O X 2$ and $T B X 3$ expression [55].

Interestingly, when miRNA expression levels were found to either increase or decline during AF development $[12,56]$, they were likewise found to be modulated by PITX2 as revealed in two distinct PITX2 loss-of-function murine models that recapitulate some aspects of the human AF. Remarkably, expression of miR-21, which negatively regulates PITX2 in atrial-derived cells [17], was downregulated in these mutant mice [46]. Of note, expression of miR-21 is upregulated in the LA of patients with long-term persistent AF as well as in a mouse model of spontaneous AF $[12,57,58]$ and after short-term AF episodes in pigs; transfection of atrial cardiomyocytes with miR-21 mimic leads to PITX2 downregulation [17]. In human patients, plasma levels of miR-21 significantly increased after AF ablation [59]. Together, these results highlight a possible reciprocal regulation between PITX2 and miR-21 in various AF settings, although the actual mechanism by which they might form feed-forward/feedback loops to propagate their adverse effects on atrial myocardium is not well understood.

PITX2 $C$ was shown to negatively regulate the expression of miR-1 in the adult mouse LA [45]. When overexpressed in normal or infarcted rat hearts, miR-1 represses the expression of potassium channel subunits and connexins and thus provokes arrhythmogenesis [60]. In the porcine model of spontaneous self-terminating AF, induced ectopic tachyarrhythmia caused rapid downregulation of PITX2C which was inversely correlated with miR-1 upregulation in the LA of paced animals [17]. In contrast, expression of miR-1 is downregulated in patients with chronic persistent AF [61]. Several lines of experimental evidence suggest that PITX2 also negatively regulates miR-29a expression in atrial myocardium $[46,62]$. Importantly, a significant increase in the expression levels of miR-29a was observed in both LA [57] and RA [63] appendages from patients with chronic AF compared to those from the sinus rhythm controls. The calcium voltage-gated channel subunit alpha1C (CACNA1C) gene, playing an essential role in cardiac arrhythmogenesis, was identified as a target gene of miR-29a in atrial myocytes [63]. In this sense, it seems reasonable to suggest that suppression of aberrant activity of miR-29a by PITX2 could ameliorate AF. 
As in the case of miRNAs, IncRNAs could also be potent regulators of AF risk factors [64]. Recently, RNA sequencing of human LA/RA pairs identified an intergenic lncRNA named PITX2 adjacent noncoding RNA (PANCR). Expression of PANCR positively correlates with PITX2C levels in human LA biopsy samples and PANCR may act as a positive regulator of PITX2C: PANCR knockdown represses PITX2C expression and in this regard mimics the consequences of PITX2C inactivation on mRNA and miRNA expression in differentiated cardiomyocytes [65].

Together, the data illustrate multiple levels of PITX2 regulation, potentially requiring further investigations of any proposed causative association between PITX2 expression levels in the human adult atria and the first clinically observable manifestations of a transient irregularity of the atrial rhythm.

\section{TBX5/miRNA circuits}

TBX5, a member of the Brachyury T-box TF family, is widely expressed in the human heart, including the atria [66]. TBX5 undergoes extensive alternative splicing, generating several transcript variants encoding protein isoforms with different properties [67, 68]. Alteration of TBX5 levels affects the expression of hundreds of genes, including genes implicated in AF pathogenesis $[69,70,71]$.

The involvement of TBX5 in human AF development was suggested through the analysis of the TBX5 gain-of-function mutation in a large family of patients with mild HoltOram syndrome (HOS) and paroxysmal AF [72, 73]. However, TBX5 loss-of-function mutations were found to be associated with a predisposition to the onset of AF in a subset of HOS patients [74]. Moreover, the TBX5 loss-of-function mutation which decreases TBX5 transcriptional activity was detected in patients with "lone" AF [75], suggesting that TBX5 haploinsufficiency could contribute to AF development. In this regard, it was recently found that $T B X 5$-knockout human cardiomyocytes are characterized by marked proarrhythmic activity [71].

The results of a number of GWAS analyses have linked intronic sequence variants of theTBX5 gene to PR interval prolongation which is a surrogate AF risk marker in patients [76]. This is in line with growing evidence showing a strong association between several SNPs in the $T B X 5$ gene and lone AF in patients $[68,77]$. Recent cis-expression quantitative trait locus analysis suggests that altered $T B X 5$ expression in the human LA plays a role in AF susceptibility [6].

Additional evidence linking TBX5 and AF has emerged from studies in murine models. In mice, adult-specific $T B X 5$ deletion causes the rapid onset of AF affecting the expression of calcium-handling and other AF-susceptibility genes in atrial cardiomyocytes. In addition, it was found that TBX5 directly activates PITX2, while TBX5 and PITX2 antagonistically regulate membrane effector genes. Most importantly, it has been demonstrated that PITX2 suppression reverses the pro-arrhythmic effects of $T B X 5$ knockdown suggesting that deficiency of both, TBX5 and PITX2 could lead to the onset of AF, but through opposite mechanisms [78]. Interestingly, PITX2 itself regulates the expression of TBX5 in cardiomyocytes [79], and PITX2 insufficiency leads to molecular and electrophysiological impairment of calcium homeostasis in the mouse LA mediated by Wnt signaling genes and miRNAs [46]. 
Some studies have shown that miRNAs can act as essential components in TBX5signaling networks at $\mathrm{AF}$, through either regulation of their expression by $T B X 5$ or regulation of $T B X 5$ itself. In mouse cardiac cells and zebrafish embryos, $T B X 5$ was found to be able to regulate the expression of several miRNAs [80] and, in particular, miR-19 [81, 82]. MiR-19 expression levels are significantly increased in the LA of patients with paroxysmal AF [83]. In the mouse heart, miR-19 is transcribed as part of the miR-17-92 cluster which expression is positively regulated by PITX2. TBX5 is a target gene of both miR-10a and miR-10b [84]. Expression of miR-10b was found to be upregulated in LA biopsies from patients with chronic AF and valvular heart disease [27] and miR-10b plasma levels are decreased in AF patients after catheter ablation [85]. In the porcine model, shortlasting atrial tachyarrhythmia was associated with significant upregulation of both miR-10a and miR-10b coupled with decreased TBX5 expression in the LA of paced animals that may be permissive for AF development [17]. TBX5-dependent enhancer lncRNAs might also be functionally involved in TBX5 regulated gene expression in atrial myocytes. Particularly, it was found that RYR2-associated cis-element RNA (RACER), a TBX5-dependent lncRNA, is required for expression of ryanodine receptor 2 (RYR2), the major calcium release channel on the sarcoplasmic reticulum in cardiomyocytes. As a whole, more than two thousand $T B X 5$-dependent ncRNAs were identified in the mouse atria by deep sequencing [86].

Together, all these data indicate that alterations in TBX5 expression levels in atrial myocardium may be a trigger for the production of the arrhythmogenic substrate.

\section{ZFHX3/miRNA circuits}

ZFHX3, the zinc finger homeobox 3 gene (formerly known as ATFB1), encodes a TF which was described as a transcriptional repressor for myogenic differentiation [87]. ZFHX3 is highly expressed in the adult mouse heart [88] and human stem cell-derived cardiomyoblasts [89]. $Z F H X 3$ regulates transcription via direct interaction with predicted AT (adenine- and thymine-rich) motifs in the promoter region of target genes.

ZFHX3 located on the human chromosome 16q22 is one of the major AF susceptibilityconferring genes found by SNP scanning in Caucasian [90], European [91], Chinese [92], and Japanese [93] populations. Recently, gene-based association tests in AF patients linked single common genetic polymorphisms of the $Z F H X 3$ gene with different AF clinical phenotypes (paroxysmal and persistent AF), LA remodeling and, in turn, with $\mathrm{AF}$ recurrence after ablation $[94,95]$.

The results coming from in vitro cell-based assays show that $Z F H X 3$ can play an important role in AF predisposition and also support GWAS data on ZFHX3 involvement in the genesis of human AF. It was found that tachypacing leads to $Z F H X 3$ downregulation in cultured atrial HL-1 myocytes. In turn, ZFHX3 knockdown in HL-1 myocytes contributes to upregulation of mediators of inflammatory signaling [96] and deregulation of calcium homeostasis underlying increased atrial arrhythmogenesis [49].

There is growing evidence that $Z F H X 3$ molecular interactions with other AFsusceptibility genes, such as PITX2 and TBX5, can markedly increase AF risk. In particular, experiments with both heart-irrelevant cell lines [97] as well as HL-1 atria-derived cells [46] revealed that silencing of $Z F H X 3$ expression significantly downregulates the expression of PITX2C. Conversely, overexpression of ZFHX3 increased PITX2C expression. Remarkably, $Z F H X 3$ knockdown also significantly increased expression of TBX5 [97]. 
ZFHX3 was predicted to be a downstream target gene of miR-1 and contains two miR-1 binding sites at its $3^{\prime}$-untranslated region; cell transfections with miR-1 mimics significantly decreased expression of $Z F H X 3$ at both mRNA and protein levels [97]. Reduced levels of miR-1 expression were found in human AF [61] suggesting this could lead to a certain degree of ZFHX3 and PITX2 upregulation in diseased atria, preventing, to some extent, further aggravation of $\mathrm{AF}$.

\section{SHOX2/miRNA circuits}

SHOX2, the short stature homeobox 2 gene, encodes a TF which controls the development and function of SAN (the primary site for initiation and maintaining of the normal sinus rhythm) located in the adult RA (Fig. 1). The human SHOX2 encodes two alternatively spliced transcripts. In a cardiac developmental context, SHOX2 functions as a pro-pacemaker factor and antagonizes the $N K X 2-5$ activity in the PV myocardium (see Fig. 1) that is well known for its arrhythmogenic capacities $[98,99]$. Transcriptome analysis did not reveal any significant differences in SHOX2 expression levels between the LA and RA in sinus rhythm patients (see Fig. 2 and references therein).

Expression analysis revealed significantly reduced $S H O X 2$ transcript levels in RA samples from patients with early-onset AF. In addition, the miR-92b-5p was identified as a putative negative regulator of $\mathrm{SHOX} 2$ expression in particular cohort of AF patients carrying a mutation in the $3^{\prime}$ untranslated region of the SHOX2 gene [100]. However, the authors of this work investigated RA tissue, while AF normally originates in the LA. In mouse models, it was shown that PITX2 which is highly expressed in the LA and PV myocardium negatively regulates $S H O X 2$ directly [44] or indirectly through upregulation of the miR-17-92/106b-25 cluster, that in turn represses SHOX2. Additionally, it was found that SHOX2 upregulation in the fetal LA promotes LA ectopic automaticity [55]. It is therefore tempting to speculate that an imbalance between the expression dosages of PITX2 and SHOX2 in the LA and PV myocardium may lead to AF. In this context, it is likely that inhibitors of excessive expression of $\mathrm{SHOX}_{2}$ in the LA could help prevent $\mathrm{AF}$ development.

\section{Concluding remarks}

Results of human AF GWAS screenings coupled with data from conditional gene manipulations in mice and cell-based functional assays identify a set of TF-miRNA coregulatory loops as putative disease modules orchestrating susceptibility to induced or spontaneous AF. These modules include PITX2, TBX5, ZFHX3, and SHOX2 TFs and their upstream and downstream miRNAs (Fig. 3). Previously, these TFs have either been implicated in cardiac development and differentiation or have been shown to be mutated in patients with different subtypes of AF. Notably, the association between these TFs is significant, implying not only a synergetic, but also a previously unrecognized opposite regulation of the expression of common downstream AF-associated genes [78]. Remarkably, there is a growing evidence suggesting that other cardiac TFs, such as NKX2$5, S R F$, and GATA-6, may be associated with or responsible for early-onset human AF [16, $101,102,103]$. 


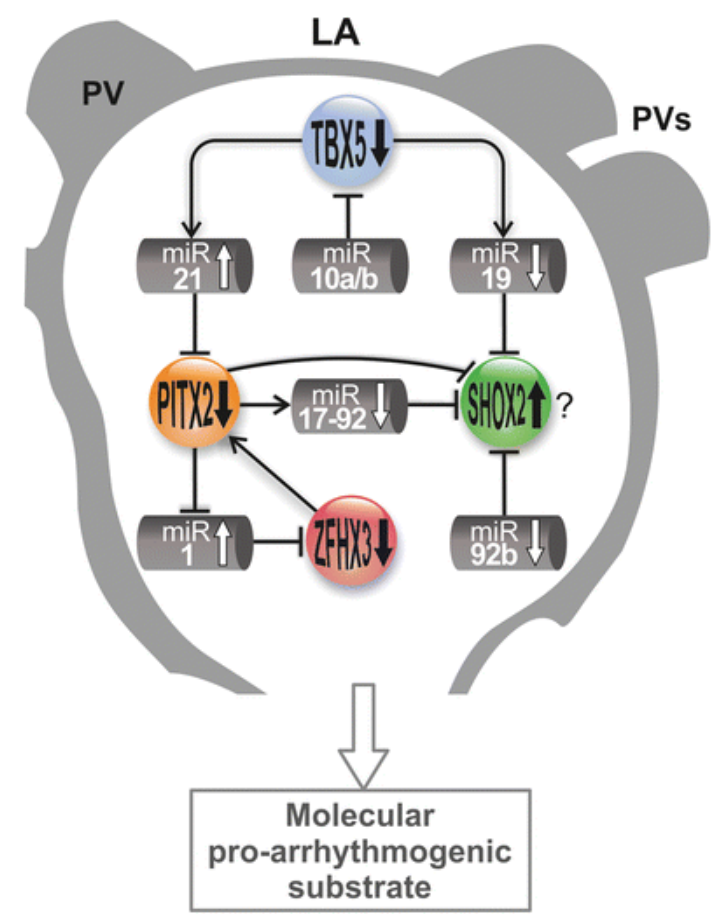

Fig. 3. Cardiac transcription factors and related microRNAs that are known or suggested to be involved in the initiation of AF. AF susceptibility, as functionally validated using in vitro and in vivo models, is associated with deregulated expression of transcription factors (PITX2, TBX5, ZFHX3, and SHOX2) and related miRNAs (miR21, miR-19, miR-17-92, and miR-92b). Bold arrows (black/white) denote either up or down expression of the genes. The question mark represents a speculative assertion that SHOX2 upregulation in the LA or PV myocardium might promote ectopic automaticity. Whether miR-10a and miR-10b are directly involved in AF predisposition remains to be experimentally determined. Of note, the miR-17-92 miRNA cluster generates a single polycistronic primary transcript that yields six mature miRNAs: miR-17, miR-18a, miR-19a, miR-19b, miR-20a, and miR-92a [107]. LA left atrium, PVs pulmonary veins

Could studies of atrial-associated TF-miRNA modules identify novel therapeutic targets and help to develop novel treatment strategies for the primary prevention of $\mathrm{AF}$ development or AF recurrence? Within each described module, a dynamic expression balance between TFs and miRNAs may have a certain clinical relevance as it was found that a low activity of PITX2, TBX5, and, probably, ZFHX3 can lead to or be associated with irregular ectopic atrial activity. In the porcine model of transitory AF, short-term atrial pacing resulted in significant upregulation of miR-21 and miR-10a/b which was associated with the downregulation of their respective target TFs, PITX2, and TBX5 [17]. In this respect, antagomiR-induced knockdown of miR-21 and $\mathrm{miR}-10 \mathrm{a} / \mathrm{b}$ might be a means to prevent recurrence of AF paroxysms. However, future studies directed at an in-depth understanding of the pathways regulated by atrial TF-miRNA circuits in various AF settings are necessary before translational treatment strategies can be considered.

Besides the role as putative therapeutic targets, the cardiac-enriched nc-RNAs discussed in the present review may be employed as prognostic and diagnostic biomarkers in AF. Indeed, it is increasingly recognized that circulating plasma miRNAs could be promising biomarkers for risk stratification in AF patients [12, 104]. In particular, plasma levels of two PITX2-associated miR partners, miR-1 and miR-21, are decreased in patients with sustained atrial tachycardia [105] and paroxysmal AF [59, 106], respectively. In contrast to miRNAs, the profiling of circulating lncRNAs is only starting to emerge as a putative biomarker tool for heart disease. 


\section{Funding information}

This work was supported in part by funds from the Institute of Health Sciences (University of A Coruña, A Coruña, Spain) and by a grant (GRC 2013/061) from the Autonomic Government of Galicia, Spain.

\section{Compliance with ethical standards}

\section{Conflict of interest}

The authors declare that they have no conflicts of interest.

\section{References}

1. Nattel S, Dobrev D (2016) Electrophysiological and molecular mechanisms of paroxysmal atrial fibrillation. Nat Rev Cardiol 13:575-590

2. Franco D, Lozano-Velasco E, Aranega A (2016) Gene regulatory networks in atrial fibrillation. World J Med Gen 6(1):16

3. Gutierrez A, Chung MK (2016) Genomics of atrial fibrillation. Curr Cardiol Rep 18:e55

4. Hayashi K, Tada H, Yamagishi M (2017) The genetics of atrial fibrillation. Curr Opin Cardiol 32:10-16

5. Christophersen IE, Rienstra M, Roselli C, Yin X, Geelhoed B, Barnard J, Lin H, Arking DE, Smith AV, Albert CM, Chaffin M, Tucker NR, Li M, Klarin D, Bihlmeyer NA, Low SK, Weeke PE, Muller-Nurasyid M, Smith JG, Brody JA, Niemeijer MN, Dorr M, Trompet S, Huffman J, Gustafsson S, Schurmann C, Kleber ME, Lyytikainen LP, Seppala I, Malik R, Horimoto A, Perez M, Sinisalo J, Aeschbacher S, Theriault S, Yao J, Radmanesh F, Weiss S, Teumer A, Choi SH, Weng LC, Clauss S, Deo R, Rader DJ, Shah SH, Sun A, Hopewell JC, Debette S, Chauhan G, Yang Q, Worrall BB, Pare G, Kamatani Y, Hagemeijer YP, Verweij N, Siland JE, Kubo M, Smith JD, Van Wagoner DR, Bis JC, Perz S, Psaty BM, Ridker PM, Magnani JW, Harris TB, Launer LJ, Shoemaker MB, Padmanabhan S, Haessler J, Bartz TM, Waldenberger M, Lichtner P, Arendt M, Krieger JE, Kahonen M, Risch L, Mansur AJ, Peters A, Smith BH, Lind L, Scott SA, Lu Y, Bottinger EB, Hernesniemi J, Lindgren CM, Wong JA, Huang J, Eskola M, Morris AP, Ford I, Reiner AP, Delgado G, Chen LY, Chen YI, Sandhu RK, Boerwinkle E, Eisele L, Lannfelt L, Rost N, Anderson CD, Taylor KD, Campbell A, Magnusson PK, Porteous D, Hocking LJ, Vlachopoulou E, Pedersen NL, Nikus K, OrhoMelander M, Hamsten A, Heeringa J, Denny JC, Kriebel J, Darbar D, Newton-Cheh C, Shaffer C, Macfarlane PW, Heilmann-Heimbach S, Almgren P, Huang PL, Sotoodehnia N, Soliman EZ, Uitterlinden AG, Hofman A, Franco OH, Volker U, Jockel KH, Sinner MF, Lin HJ, Guo X, Dichgans M, Ingelsson E, Kooperberg C, Melander O, Loos RJF, Laurikka J, Conen D, Rosand J, van der Harst P, Lokki ML, Kathiresan S, Pereira A, Jukema JW, Hayward C, Rotter JI, Marz W, Lehtimaki T, Stricker BH, Chung MK, Felix SB, Gudnason V, Alonso A, Roden DM, Kaab S, Chasman DI, Heckbert SR, Benjamin EJ, Tanaka T, Lunetta KL, Lubitz SA, Ellinor PT (2017) Large-scale analyses of common and rare variants identify 12 new loci associated with atrial fibrillation. Nat Genet 49:946-952

6. Hsu J, Gore-Panter S, Tchou G, Castel L, Lovano B, Moravec CS, Pettersson GB, Roselli EE, Gillinov AM, McCurry KR, Smedira NG, Barnard J, Van Wagoner DR, Chung MK, Smith JD (2018) Genetic control of left atrial gene expression yields insights into the genetic susceptibility for atrial fibrillation. Circ Genom Precis Med 11:e002107

7. Kataoka M, Wang DZ (2014) Non-coding RNAs including miRNAs and lncRNAs in cardiovascular biology and disease. Cell 3:883-898

8. Thum T, Condorelli G (2015) Long noncoding RNAs and microRNAs in cardiovascular pathophysiology. Circ Res 116:751-762

9. Beermann J, Piccoli MT, Viereck J, Thum T (2016) Non-coding RNAs in development and disease: background, mechanisms, and therapeutic approaches. Physiol Rev 96:1297-1325

10. Tao H, Shi KH, Yang JJ, Li J (2016) Epigenetic mechanisms in atrial fibrillation: new insights and future directions. Trends Cardiovasc Med 26:306-318

11. Molina CE, Voigt N (2017) Finding Ms or Mr Right: which miRNA to target in AF? J Mol Cell Cardiol 102:22-25 
12. van den Berg NWE, Kawasaki M, Berger WR, Neefs J, Meulendijks E, Tijsen AJ, de Groot JR (2017) MicroRNAs in atrial fibrillation: from expression signatures to functional implications. Cardiovasc Drugs Ther 31:345-365

13. Su Y, Li L, Zhao S, Yue Y, Yang S (2018) The long noncoding RNA expression profiles of paroxysmal atrial fibrillation identified by microarray analysis. Gene 642:125-134

14. Li Z, Wang X, Wang W, Du J, Wei J, Zhang Y, Wang J, Hou Y (2017) Altered long noncoding RNA expression profile in rabbit atria with atrial fibrillation: TCONS_00075467 modulates atrial electrical remodeling by sponging miR-328 to regulate CACNA1C. J Mol Cell Cardiol 108:73-85

15. Mauro VD, Barandalla-Sobrados M, Catalucci D (2018) The noncoding-RNA landscape in cardiovascular health and disease. Non-coding RNA Res 3:12-19

16. Deshmukh A, Barnard J, Sun H, Newton D, Castel L, Pettersson G, Johnston D, Roselli E, Gillinov AM, McCurry K, Moravec C, Smith JD, Van Wagoner DR, Chung MK (2015) Left atrial transcriptional changes associated with atrial fibrillation susceptibility and persistence. Circ Arrhythm Electrophysiol 8:32-41

17. Torrado M, Franco D, Lozano-Velasco E, Hernandez-Torres F, Calvino R, Aldama G, Centeno A, Castro-Beiras A, Mikhailov A (2015) A microRNA-transcription factor blueprint for early atrial arrhythmogenic remodeling. Biomed Res Int 2015:e263151

18. Staerk L, Sherer JA, Ko D, Benjamin EJ, Helm RH (2017) Atrial fibrillation: epidemiology, pathophysiology, and clinical outcomes. Circ Res 120:1501-1517

19. Hasebe H, Yoshida K, Iida M, Hatano N, Muramatsu T, Aonuma K (2016) Right-to-left frequency gradient during atrial fibrillation initiated by right atrial ectopies and its augmentation by adenosine triphosphate: implications of right atrial fibrillation. Heart Rhythm 13:354-363

20. Di Biase L, Burkhardt JD, Mohanty P, Sanchez J, Mohanty S, Horton R, Gallinghouse GJ, Bailey SM, Zagrodzky JD, Santangeli P, Hao S, Hongo R, Beheiry S, Themistoclakis S, Bonso A, Rossillo A, Corrado A, Raviele A, Al-Ahmad A, Wang P, Cummings JE, Schweikert RA, Pelargonio G, Dello Russo A, Casella M, Santarelli P, Lewis WR, Natale A (2010) Left atrial appendage: an underrecognized trigger site of atrial fibrillation. Circulation 122:109-118

21. Burnett LA, Kocheril AG (2014) Putative role of right atrial ablation in atrial fibrillation. J Atr Fibrillation 6:e1085

22. Krummen DE, Hebsur S, Salcedo J, Narayan SM, Lalani GG, Schricker AA (2015) Mechanisms underlying AF: triggers, rotors, other? Curr Treat Options Cardiovasc Med 17:e371

23. Kahr PC, Piccini I, Fabritz L, Greber B, Scholer H, Scheld HH, Hoffmeier A, Brown NA, Kirchhof P (2011) Systematic analysis of gene expression differences between left and right atria in different mouse strains and in human atrial tissue. PLoS One 6:e26389

24. Hsu J, Hanna P, Van Wagoner DR, Barnard J, Serre D, Chung MK, Smith JD (2012) Whole genome expression differences in human left and right atria ascertained by RNA sequencing. Circ Cardiovasc Genet 5:327-335

25. Lin H, Dolmatova EV, Morley MP, Lunetta KL, McManus DD, Magnani JW, Margulies KB, Hakonarson H, del Monte F, Benjamin EJ, Cappola TP, Ellinor PT (2014) Gene expression and genetic variation in human atria. Heart Rhythm 11:266-271

26. Slagsvold KH, Johnsen AB, Rognmo O, Hoydal M, Wisloff U, Wahba A (2014) Comparison of left versus right atrial myocardium in patients with sinus rhythm or atrial fibrillation - an assessment of mitochondrial function and microRNA expression. Physiol Rep 2:e12124

27. Cooley N, Cowley MJ, Lin RC, Marasco S, Wong C, Kaye DM, Dart AM, Woodcock EA (2012) Influence of atrial fibrillation on microRNA expression profiles in left and right atria from patients with valvular heart disease. Physiol Genomics 44:211-219

28. Hatem SN, Redheuil A, Gandjbakhch E (2016) Cardiac adipose tissue and atrial fibrillation: the perils of adiposity. Cardiovasc Res 109:502-509

29. Suffee N, Moore-Morris T, Farahmand P, Rucker-Martin C, Dilanian G, Fradet M, Sawaki D, Derumeaux G, LePrince P, Clement K, Dugail I, Puceat M, Hatem SN (2017) Atrial natriuretic peptide regulates adipose tissue accumulation in adult atria. Proc Natl Acad Sci U S A 114:E771-E780

30. Zangi L, Oliveira MS, Ye LY, Ma Q, Sultana N, Hadas Y, Chepurko E, Spater D, Zhou B, Chew WL, Ebina W, Abrial M, Wang QD, Pu WT, Chien KR (2017) Insulin-like growth factor 1 receptor-dependent pathway drives epicardial adipose tissue formation after myocardial injury. Circulation 135:59-72

31. Kirchhof P, Kahr PC, Kaese S, Piccini I, Vokshi I, Scheld HH, Rotering H, Fortmueller L, Laakmann S, Verheule S, Schotten U, Fabritz L, Brown NA (2011) PITX2c is expressed in the adult left atrium, and reducing Pitx2c expression promotes atrial fibrillation inducibility and complex changes in gene expression. Circ Cardiovasc Genet 4:123-133 
32. Torrado M, Franco D, Hernandez-Torres F, Crespo-Leiro MG, Iglesias-Gil C, Castro-Beiras A, Mikhailov AT (2014) Pitx2c is reactivated in the failing myocardium and stimulates myf5 expression in cultured cardiomyocytes. PLoS One 9:e90561

33. Gore-Panter SR, Hsu J, Hanna P, Gillinov AM, Pettersson G, Newton DW, Moravec CS, Van Wagoner DR, Chung MK, Barnard J, Smith JD (2014) Atrial fibrillation associated chromosome 4q25 variants are not associated with PITX2c expression in human adult left atrial appendages. PLoS One 9:e86245

34. Campione M, Franco D (2016) Current perspectives in cardiac laterality. J Cardiovasc Dev Dis 3(4):34. https://doi.org/10.3390/jcdd3040034

35. Franco D, Sedmera D, Lozano-Velasco E (2017) Multiple roles of Pitx2 in cardiac development and disease. J Cardiovasc Dev Dis 4(4):16. https://doi.org/10.3390/jcdd4040016

36. Mommersteeg MT, Hoogaars WM, Prall OW, de Gier-de Vries C, Wiese C, Clout DE, Papaioannou VE, Brown NA, Harvey RP, Moorman AF, Christoffels VM (2007) Molecular pathway for the localized formation of the sinoatrial node. Circ Res 100:354-362

37. Wu MH, Wang JK, Lin JL, Lai LP, Lue HC, Young ML, Hsieh FJ (1998) Supraventricular tachycardia in patients with right atrial isomerism. J Am Coll Cardiol 32:773-779

38. Syeda F, Kirchhof P, Fabritz L (2017) PITX2-dependent gene regulation in atrial fibrillation and rhythm control. J Physiol 595:4019-4026

39. Mommersteeg MT, Brown NA, Prall OW, de Gier-de Vries C, Harvey RP, Moorman AF, Christoffels VM (2007) Pitx2c and Nkx2-5 are required for the formation and identity of the pulmonary myocardium. Circ Res 101:902-909

40. Lubitz SA, Lunetta KL, Lin H, Arking DE, Trompet S, Li G, Krijthe BP, Chasman DI, Barnard J, Kleber ME, Dorr M, Ozaki K, Smith AV, Muller-Nurasyid M, Walter S, Agarwal SK, Bis JC, Brody JA, Chen LY, Everett BM, Ford I, Franco OH, Harris TB, Hofman A, Kaab S, Mahida S, Kathiresan S, Kubo M, Launer LJ, MacFarlane PW, Magnani JW, McKnight B, McManus DD, Peters A, Psaty BM, Rose LM, Rotter JI, Silbernagel G, Smith JD, Sotoodehnia N, Stott DJ, Taylor KD, Tomaschitz A, Tsunoda T, Uitterlinden AG, Van Wagoner DR, Volker U, Volzke H, Murabito JM, Sinner MF, Gudnason V, Felix SB, Marz W, Chung M, Albert CM, Stricker BH, Tanaka T, Heckbert SR, Jukema JW, Alonso A, Benjamin EJ, Ellinor PT (2014) Novel genetic markers associate with atrial fibrillation risk in Europeans and Japanese. J Am Coll Cardiol 63:1200-1210

41. Ye J, Tucker NR, Weng LC, Clauss S, Lubitz SA, Ellinor PT (2016) A functional variant associated with atrial fibrillation regulates PITX2c expression through TFAP2a. Am J Hum Genet 99:1281-1291

42. Wang J, Zhang DF, Sun YM, Yang YQ (2014) A novel PITX2c loss-of-function mutation associated with familial atrial fibrillation. Eur J Med Genet 57:25-31

43. Tsai CT, Hsieh CS, Chang SN, Chuang EY, Juang JM, Lin LY, Lai LP, Hwang JJ, Chiang FT, Lin JL (2015) Next-generation sequencing of nine atrial fibrillation candidate genes identified novel de novo mutations in patients with extreme trait of atrial fibrillation. J Med Genet 52:2836

44. Wang J, Klysik E, Sood S, Johnson RL, Wehrens XH, Martin JF (2010) Pitx2 prevents susceptibility to atrial arrhythmias by inhibiting left-sided pacemaker specification. Proc Natl Acad Sci U S A 107:9753-9758

45. Chinchilla A, Daimi H, Lozano-Velasco E, Dominguez JN, Caballero R, Delpon E, Tamargo J, Cinca J, Hove-Madsen L, Aranega AE, Franco D (2011) PITX2 insufficiency leads to atrial electrical and structural remodeling linked to arrhythmogenesis. Circ Cardiovasc Genet 4:269279

46. Lozano-Velasco E, Hernandez-Torres F, Daimi H, Serra SA, Herraiz A, Hove-Madsen L, Aranega A, Franco D (2016) Pitx2 impairs calcium handling in a dose-dependent manner by modulating Wnt signalling. Cardiovasc Res 109:55-66

47. Tao Y, Zhang M, Li L, Bai Y, Zhou Y, Moon AM, Kaminski HJ, Martin JF (2014) Pitx2, an atrial fibrillation predisposition gene, directly regulates ion transport and intercalated disc genes. Circ Cardiovasc Genet 7:23-32

48. Scridon A, Fouilloux-Meugnier E, Loizon E, Rome S, Julien C, Barres C, Chevalier P (2014) Long-standing arterial hypertension is associated with Pitx2 down-regulation in a rat model of spontaneous atrial tachyarrhythmias. Europace 17:160-165

49. Kao YH, Hsu JC, Chen YC, Lin YK, Lkhagva B, Chen SA, Chen YJ (2016) ZFHX3 knockdown increases arrhythmogenesis and dysregulates calcium homeostasis in HL-1 atrial myocytes. Int J Cardiol 210:85-9250.

50. Perez-Hernandez M, Matamoros M, Barana A, Amoros I, Gomez R, Nunez M, Sacristan S, Pinto A, Fernandez-Aviles F, Tamargo J, Delpon E, Caballero R (2016) Pitx2c increases in 
atrial myocytes from chronic atrial fibrillation patients enhancing $\mathrm{I}_{\mathrm{Ks}}$ and decreasing $\mathrm{I}_{\mathrm{Ca}, \mathrm{L}}$. Cardiovasc Res 109:431-441

51. Doñate Puertas R, Meugnier E, Romestaing C, Rey C, Morel E, Lachuer J, Gadot N, Scridon A, Julien C, Tronc F, Chapuis B, Valla C, Janin A, Pirola L, Méjat A, Rome S, Chevalier P (2017) Atrial fibrillation is associated with hypermethylation in human left atrium, and treatment with decitabine reduces atrial tachyarrhythmias in spontaneously hypertensive rats. Transl Res 184:57-67

52. Syeda F, Holmes AP, Yu TY, Tull S, Kuhlmann SM, Pavlovic D, Betney D, Riley G, Kucera JP, Jousset F, de Groot JR, Rohr S, Brown NA, Fabritz L, Kirchhof P (2016) PITX2 modulates atrial membrane potential and the antiarrhythmic effects of sodium-channel blockers. J Am Coll Cardiol 68:1881-1894

53. Martin RI, Babaei MS, Choy MK, Owens WA, Chico TJ, Keenan D, Yonan N, Koref MS, Keavney BD (2015) Genetic variants associated with risk of atrial fibrillation regulate expression of PITX2, CAV1, MYOZ1, C9orf3 and FANCC. J Mol Cell Cardiol 85:207-214

54. Li N, Dobrev D, Wehrens XH (2016) PITX2: a master regulator of cardiac channelopathy in atrial fibrillation? Cardiovasc Res 109:345-347

55. Wang J, Bai Y, Li N, Ye W, Zhang M, Greene SB, Tao Y, Chen Y, Wehrens XH, Martin JF (2014) Pitx2-microRNA pathway that delimits sinoatrial node development and inhibits predisposition to atrial fibrillation. Proc Natl Acad Sci U S A 111:9181-9186

56. Santulli G, Iaccarino G, De Luca N, Trimarco B, Condorelli G (2014) Atrial fibrillation and microRNAs. Front Physiol 5:e15

57. Adam O, Lohfelm B, Thum T, Gupta SK, Puhl SL, Schafers HJ, Bohm M, Laufs U (2012) Role of miR-21 in the pathogenesis of atrial fibrosis. Basic Res Cardiol 107:e278

58. Barana A, Matamoros M, Dolz-Gaiton P, Perez-Hernandez M, Amoros I, Nunez M, Sacristan S, Pedraz A, Pinto A, Fernandez-Aviles F, Tamargo J, Delpon E, Caballero R (2014) Chronic atrial fibrillation increases microRNA-21 in human atrial myocytes decreasing L-type calcium current. Circ Arrhythm Electrophysiol 7:861-868

59. McManus DD, Tanriverdi K, Lin H, Esa N, Kinno M, Mandapati D, Tam S, Okike ON, Ellinor PT, Keaney JF Jr, Donahue JK, Benjamin EJ, Freedman JE (2015) Plasma microRNAs are associated with atrial fibrillation and change after catheter ablation (the miRhythm study). Heart Rhythm 12:3-10

60. Yang B, Lin H, Xiao J, Lu Y, Luo X, Li B, Zhang Y, Xu C, Bai Y, Wang H, Chen G, Wang Z (2007) The muscle-specific microRNA miR-1 regulates cardiac arrhythmogenic potential by targeting GJA1 and KCNJ2. Nat Med 13:486-491

61. Girmatsion Z, Biliczki P, Bonauer A, Wimmer-Greinecker G, Scherer M, Moritz A, Bukowska A, Goette A, Nattel S, Hohnloser SH, Ehrlich JR (2009) Changes in microRNA-1 expression and IK1 up-regulation in human atrial fibrillation. Heart Rhythm 6:1802-1809

62. Lozano-Velasco E, Wangensteen R, Quesada A, Garcia-Padilla C, Osorio JA, Ruiz-Torres MD, Aranega A, Franco D (2017) Hyperthyroidism, but not hypertension, impairs PITX2 expression leading to Wnt-microRNA-ion channel remodeling. PLoS One 12:e0188473

63. Zhao Y, Yuan Y, Qiu C (2016) Underexpression of CACNA1C caused by overexpression of microRNA-29a underlies the pathogenesis of atrial fibrillation. Med Sci Monit 22:2175-2181

64. Xu Y, Huang R, Gu J, Jiang W (2016) Identification of long non-coding RNAs as novel biomarker and potential therapeutic target for atrial fibrillation in old adults. Oncotarget 7:10803-10811

65. Gore-Panter SR, Hsu J, Barnard J, Moravec CS, Van Wagoner DR, Chung MK, Smith JD (2016) PANCR, the PITX2 adjacent noncoding RNA, is expressed in human left atria and regulates PITX2c expression. Circ Arrhythm Electrophysiol 9:e003197

66. Hatcher CJ, Goldstein MM, Mah CS, Delia CS, Basson CT (2000) Identification and localization of TBX5 transcription factor during human cardiac morphogenesis. Dev Dyn 219:90-95

67. Georges R, Nemer G, Morin M, Lefebvre C, Nemer M (2008) Distinct expression and function of alternatively spliced Tbx5 isoforms in cell growth and differentiation. Mol Cell Biol 28:4052-4067

68. Zhu T, Qiao L, Wang Q, Mi R, Chen J, Lu Y, Gu J, Zheng Q (2017) T-box family of transcription factor-TBX5, insights in development and disease. Am J Transl Res 9:442-453

69. Mori AD, Zhu Y, Vahora I, Nieman B, Koshiba-Takeuchi K, Davidson L, Pizard A, Seidman JG, Seidman CE, Chen XJ, Henkelman RM, Bruneau BG (2006) Tbx5-dependent rheostatic control of cardiac gene expression and morphogenesis. Dev Biol 297:566-586

70. Tan N, Chung MK, Smith JD, Hsu J, Serre D, Newton DW, Castel L, Soltesz E, Pettersson G, Gillinov AM, Van Wagoner DR, Barnard J (2013) Weighted gene coexpression network 
analysis of human left atrial tissue identifies gene modules associated with atrial fibrillation. Circ Cardiovasc Genet 6:362-371

71. Karakikes I, Termglinchan V, Cepeda DA, Lee J, Diecke S, Hendel A, Itzhaki I, Ameen M, Shrestha R, Wu H, Ma N, Shao NY, Seeger T, Woo N, Wilson KD, Matsa E, Porteus MH, Sebastiano V, Wu JC (2017) A comprehensive TALEN-based knockout library for generating human-induced pluripotent stem cell-based models for cardiovascular diseases. Circ Res 120:1561-1571

72. Postma AV, van de Meerakker JB, Mathijssen IB, Barnett P, Christoffels VM, Ilgun A, Lam J, Wilde AA, Lekanne Deprez RH, Moorman AF (2008) A gain-of-function TBX5 mutation is associated with atypical Holt-Oram syndrome and paroxysmal atrial fibrillation. Circ Res 102:1433-1442

73. Ma JF, Yang F, Mahida SN, Zhao L, Chen X, Zhang ML, Sun Z, Yao Y, Zhang YX, Zheng GY, Dong J, Feng MJ, Zhang R, Sun J, Li S, Wang QS, Cao H, Benjamin EJ, Ellinor PT, Li YG, Tian XL (2016) TBX5 mutations contribute to early-onset atrial fibrillation in Chinese and Caucasians. Cardiovasc Res 109:442-450

74. Guo DF, Li RG, Yuan F, Shi HY, Hou XM, Qu XK, Xu YJ, Zhang M, Liu X, Jiang JQ, Yang YQ, Qiu XB (2016) TBX5 loss-of-function mutation contributes to atrial fibrillation and atypical Holt-Oram syndrome. Mol Med Rep 13:4349-4356

75. Wang ZC, Ji WH, Ruan CW, Liu XY, Qiu XB, Yuan F, Li RG, Xu YJ, Liu X, Huang RT, Xue S, Yang YQ (2016) Prevalence and spectrum of TBX5 mutation in patients with lone atrial fibrillation. Int J Med Sci 13:60-67

76. Holm H, Gudbjartsson DF, Arnar DO, Thorleifsson G, Thorgeirsson G, Stefansdottir H, Gudjonsson SA, Jonasdottir A, Mathiesen EB, Njolstad I, Nyrnes A, Wilsgaard T, Hald EM, Hveem K, Stoltenberg C, Lochen ML, Kong A, Thorsteinsdottir U, Stefansson K (2010) Several common variants modulate heart rate, PR interval and QRS duration. Nat Genet 42:117-122

77. Zhang R, Tian X, Gao L, Li H, Yin X, Dong Y, Yang Y, Xia Y (2016) Common variants in the TBX5 gene associated with atrial fibrillation in a Chinese Han population. PLoS One 11:e0160467

78. Nadadur RD, Broman MT, Boukens B, Mazurek SR, Yang X, van den Boogaard M, Bekeny J, Gadek M, Ward T, Zhang M, Qiao Y, Martin JF, Seidman CE, Seidman J, Christoffels V, Efimov IR, McNally EM, Weber CR, Moskowitz IP (2016) Pitx2 modulates a Tbx5-dependent gene regulatory network to maintain atrial rhythm. Sci Transl Med 8:e354ra115

79. Lozano-Velasco E, Chinchilla A, Martinez-Fernandez S, Hernandez-Torres F, Navarro F, Lyons GE, Franco D, Aranega AE (2011) Pitx2c modulates cardiac-specific transcription factors networks in differentiating cardiomyocytes from murine embryonic stem cells. Cells Tissues Organs 194:349-362

80. D'Aurizio R, Russo F, Chiavacci E, Baumgart M, Groth M, D’Onofrio M, Arisi I, Rainaldi G, Pitto L, Pellegrini M (2016) Discovering miRNA regulatory networks in Holt-Oram syndrome using a zebrafish model. Front Bioeng Biotechnol 4:e60

81. Chiavacci E, Dolfi L, Verduci L, Meghini F, Gestri G, Evangelista AM, Wilson SW, Cremisi F, Pitto L (2012) MicroRNA 218 mediates the effects of Tbx5a over-expression on zebrafish heart development. PLoS One 7:e50536

82. Chiang DY, Zhang M, Voigt N, Alsina KM, Jakob H, Martin JF, Dobrev D, Wehrens XH, Li N (2015) Identification of microRNA-mRNA dysregulations in paroxysmal atrial fibrillation. Int $\mathrm{J}$ Cardiol 184C:190-197

83. Wang J, Song S, Xie C, Han J, Li Y, Shi J, Xin M, Luo T, Meng X, Yang B (2015) MicroRNA profiling in the left atrium in patients with non-valvular paroxysmal atrial fibrillation. BMC Cardiovasc Disord 15:e97

84. Wang F, Yang XY, Zhao JY, Yu LW, Zhang P, Duan WY, Chong M, Gui YH (2014) miR-10a and miR-10b target the 3'-untranslated region of TBX5 to repress its expression. Pediatr Cardiol 35:1072-1079

85. Vaze A, Donahue K, Spring M, Sardana M, Tanriverdi K, Freedman JE, Keaney JF, Benjamin EJ, Lubitz SA, Rosenthal L, Floyd K, McManus DD (2017) Plasma microRNAs relate to atrial fibrillation recurrence after catheter ablation: longitudinal findings from the MiRhythm study. $\mathrm{J}$ Clin Exp Cardiol 8:502

86. Yang XH, Nadadur RD, Hilvering CR, Bianchi V, Werner M, Mazurek SR, Gadek M, Shen KM, Goldman JA, Tyan L, Bekeny J, Hall JM, Lee N, Perez-Cervantes C, Burnicka-Turek O, Poss KD, Weber CR, de Laat W, Ruthenburg AJ, Moskowitz IP (2017) Transcription-factordependent enhancer transcription defines a gene regulatory network for cardiac rhythm. Elife 6:e.31683 
87. Berry FB, Miura Y, Mihara K, Kaspar P, Sakata N, Hashimoto-Tamaoki T, Tamaoki T (2001) Positive and negative regulation of myogenic differentiation of $\mathrm{C} 2 \mathrm{C} 12$ cells by isoforms of the multiple homeodomain zinc finger transcription factor ATBF1. J Biol Chem 276:25057-25065

88. Ido A, Miura Y, Watanabe M, Sakai M, Inoue Y, Miki T, Hashimoto T, Morinaga T, Nishi S, Tamaoki T (1996) Cloning of the cDNA encoding the mouse ATBF1 transcription factor. Gene 168:227-231

89. den Hartogh SC, Wolstencroft K, Mummery CL, Passier R (2016) A comprehensive gene expression analysis at sequential stages of in vitro cardiac differentiation from isolated MESP1expressing-mesoderm progenitors. Sci Rep 6:e19386

90. Zhai C, Cong H, Liu Y, Zhang Y, Liu X, Zhang H, Ren Z (2015) Rs7193343 polymorphism in zinc finger homeobox 3 (ZFHX3) gene and atrial fibrillation: an updated meta-analysis of 10 case-control comparisons. BMC Cardiovasc Disord 15:e58

91. Benjamin EJ, Rice KM, Arking DE, Pfeufer A, van Noord C, Smith AV, Schnabel RB, Bis JC, Boerwinkle E, Sinner MF, Dehghan A, Lubitz SA, D’Agostino RB Sr, Lumley T, Ehret GB, Heeringa J, Aspelund T, Newton-Cheh C, Larson MG, Marciante KD, Soliman EZ, Rivadeneira F, Wang TJ, Eiriksdottir G, Levy D, Psaty BM, Li M, Chamberlain AM, Hofman A, Vasan RS, Harris TB, Rotter JI, Kao WH, Agarwal SK, Stricker BH, Wang K, Launer LJ, Smith NL, Chakravarti A, Uitterlinden AG, Wolf PA, Sotoodehnia N, Kottgen A, van Duijn CM, Meitinger T, Mueller M, Perz S, Steinbeck G, Wichmann HE, Lunetta KL, Heckbert SR, Gudnason V, Alonso A, Kaab S, Ellinor PT, Witteman JC (2009) Variants in ZFHX3 are associated with atrial fibrillation in individuals of European ancestry. Nat Genet 41:879-881

92. Liu Y, Ni B, Lin Y, Chen XG, Fang Z, Zhao L, Hu Z, Zhang F (2014) Genetic polymorphisms in ZFHX3 are associated with atrial fibrillation in a Chinese Han population. PLoS One 9:e101318

93. Zaw KTT, Sato N, Ikeda S, Thu KS, Mieno MN, Arai T, Mori S, Furukawa T, Sasano T, Sawabe M, Tanaka M, Muramatsu M (2016) Association of ZFHX3 gene variation with atrial fibrillation, cerebral infarction, and lung thromboembolism: an autopsy study. J Cardiol 70:180-184

94. Shim J, Uhm JS, Joung B, Lee MH, Pak HN (2016) 4q25 and ZFHX3 single nucleotide polymorphisms are associated with electroanatomical characteristics of left atrium and clinical outcomes of radiofrequency catheter ablation in patients with atrial fibrillation. Int J Arrhythm 17:118-134

95. Husser D, Buttner P, Ueberham L, Dinov B, Sommer P, Arya A, Hindricks G, Bollmann A (2017) Association of atrial fibrillation susceptibility genes, atrial fibrillation phenotypes and response to catheter ablation: a gene-based analysis of GWAS data. J Transl Med 15:71

96. Jiang Q, Ni B, Shi J, Han Z, Qi R, Xu W, Wang D, Wang DW, Chen M (2014) Downregulation of ATBF1 activates STAT3 signaling via PIAS3 in pacing-induced HL-1 atrial myocytes. Biochem Biophys Res Commun 449:278-283

97. Huang Y, Wang C, Yao Y, Zuo X, Chen S, Xu C, Zhang H, Lu Q, Chang L, Wang F, Wang P, Zhang R, Hu Z, Song Q, Yang X, Li C, Li S, Zhao Y, Yang Q, Yin D, Wang X, Si W, Li X, Xiong X, Wang D, Luo C, Li J, Wang J, Chen J, Wang L, Han M, Ye J, Chen F, Liu J, Liu Y, Wu G, Yang B, Cheng X, Liao Y, Wu Y, Ke T, Chen Q, Tu X, Elston R, Rao S, Yang Y, Xia Y, Wang QK (2015) Molecular basis of gene-gene interaction: cyclic cross-regulation of gene expression and post-GWAS gene-gene interaction involved in atrial fibrillation. PLoS Genet 11:e1005393

98. Ye W, Song Y, Huang Z, Zhang Y, Chen Y (2015) Genetic regulation of Sinoatrial node development and pacemaker program in the venous pole. J Cardiovasc Dev Dis 2:282-298

99. Ye W, Wang J, Song Y, Yu D, Sun C, Liu C, Chen F, Zhang Y, Wang F, Harvey RP, Schrader L, Martin JF, Chen Y (2015) A common Shox2-Nkx2-5 antagonistic mechanism primes the pacemaker cell fate in the pulmonary vein myocardium and sinoatrial node. Development 142:2521-2532

100. Hoffmann S, Clauss S, Berger IM, Weiss B, Montalbano A, Roth R, Bucher M, Klier I, Wakili R, Seitz H, Schulze-Bahr E, Katus HA, Flachsbart F, Nebel A, Guenther SP, Bagaev E, Rottbauer W, Kaab S, Just S, Rappold GA (2016) Coding and non-coding variants in the SHOX2 gene in patients with early-onset atrial fibrillation. Basic Res Cardiol 111:e36

101. Zhou M, Liao Y, Tu X (2015) The role of transcription factors in atrial fibrillation. J Thorac Dis 7:152-158

102. Campuzano O, Perez-Serra A, Iglesias A, Brugada R (2016) Genetic basis of atrial fibrillation. Genes Dis 3:257-262

103. Fatkin D, Santiago CF, Huttner IG, Lubitz SA, Ellinor PT (2017) Genetics of atrial fibrillation: state of the art in 2017. Heart Lung Circ 26:894-901 
104. da Silva AM, de Araujo JN, de Freitas RC, Silbiger VN (2017) Circulating MicroRNAs as potential biomarkers of atrial fibrillation. Biomed Res Int 2017:7804763

105. Sun L, Sun S, Zeng S, Li Y, Pan W, Zhang Z (2015) Expression of circulating microRNA-1 and microRNA-133 in pediatric patients with tachycardia. Mol Med Rep 11:4039-4046

106. Liu Z, Zhou C, Liu Y, Wang S, Ye P, Miao X, Xia J (2012) The expression levels of plasma micoRNAs in atrial fibrillation patients. PLoS One 7:e44906107.

107. Mogilyansky E, Rigoutsos I (2013) The miR-17/92 cluster: a comprehensive update on its genomics, genetics, functions and increasingly important and numerous roles in health and disease. Cell Death Differ 20:1603-1614 